\title{
Case report: maternal mosaicism resulting in inheritance of a novel GATA6 mutation causing pancreatic agenesis and neonatal diabetes mellitus
}

Daphne Yau', Elisa De Franco ${ }^{2}$, Sarah E. Flanagan², Sian Ellard ${ }^{2}$, Miriam Blumenkrantz $^{3}$ and John J. Mitchell ${ }^{{ }^{*}}$

\begin{abstract}
Background: Haploinsufficiency of the GATA6 transcription factor gene was recently found to be the most common cause of pancreatic agenesis, a rare cause of neonatal diabetes mellitus. Although most cases are de novo, we describe three siblings with inherited GATA6 haploinsufficiency and the rare finding of parental mosaicism.

Case Presentation: The proband was born at term with severe intrauterine growth restriction, the first child of non-consanguineous parents. Diabetes occurred on day of life 1 with pancreatic exocrine insufficiency noted at several months of age. Pancreatic agenesis with absent gallbladder was confirmed when he underwent congenital diaphragmatic hernia and intestinal malrotation repair. A patent ductus arteriosus and pulmonary stenosis were repaired in infancy. Neurocognitive development has been normal. A second pregnancy was terminated due to tetralogy of Fallot and pulmonary hypoplasia secondary to congenital diaphragmatic hernia. The fetus also demonstrated severe pancreatic hypoplasia, gallbladder agenesis and intestinal rotation abnormalities. Despite severe hypoplasia, the pancreas demonstrated normal islet histology. Another sibling was found to have multiple cardiac abnormalities, requiring procedural intervention. Given the proband's spectrum of congenital anomalies, Sanger sequencing of the GATA6 gene was performed, revealing a novel heterozygous c.635_660del frameshift mutation (p.Pro212fs). The mutation is predicted to be pathogenic, resulting in inclusion of a premature stop codon and likely degradation of the gene transcript by nonsense-mediated decay. The abortus and the sibling with the cardiac defect were both found to have the mutation, while the father and remaining sibling were negative. The mother, who is healthy with no evidence of diabetes or cardiac disease, is mosaic for the mutation at a level of $11 \%$ in her peripheral leukocytes by next-generation sequencing.

Conclusion: We highlight a rare mechanism of pancreatic agenesis, this being only the second report of parental mosaicism for a GATA6 mutation and one of a handful of inherited cases. We also further define the phenotypic variability of GATA6 haploinsufficiency, even in individuals carrying the same mutation. Mutations in GATA6 should be strongly considered in cases of diabetes due to pancreatic hypoplasia or agenesis, and potentially affected family members should be tested regardless of phenotype.
\end{abstract}

Keywords: GATA6, Haploinsufficiency, Mosaicism, Pancreas abnormalities, Neonatal diabetes mellitus

\footnotetext{
* Correspondence: john.mitchell@muhc.mcgill.ca

'Division of Pediatric Endocrinology Montreal Children's Hospital, McGill

University Health Centre, 1001 Boulevard Decarie, Montreal H4A 3J1, Quebec,

Canada

Full list of author information is available at the end of the article
} 


\section{Background}

Although type 1 diabetes mellitus accounts for the vast majority of pediatric diabetes, monogenic forms account for up to $4 \%$ of cases $[1,2]$. The latter are due to single gene defects affecting pancreatic $\beta$-cell function, development or survival and include neonatal diabetes mellitus (NDM). NDM is defined as diabetes occurring in the first six months of life and occurs with an estimated frequency of approximately 1:100 000 live births [2-5]. Both transient and permanent forms of NDM exist (Table 1). Although clinically indistinguishable from each other at presentation, most transient cases resolve at a median age of 12 weeks but relapse in 50-60\% $[6,7]$. Different genetic loci and genes are associated with transient versus permanent NDM. Methylation abnormalities at chromosome $6 \mathrm{q} 24$ account for two thirds of transient cases, while in permanent NDM, activating mutations in $A B C C 8$ and $K C N J 11$ are the most common genetic defects in outbred populations and EIF2AK3 is the most frequent in consanguineous groups [3, 7]. KCNJ11 and ABCC8 encode the KIR6.2 and SUR1 subunits of the $\mathrm{K}_{\mathrm{ATP}}$ channel, respectively, which links glucose metabolism to insulin secretion. EIF2AK3 encodes a kinase involved in regulating the endoplasmic reticulum stress response to misfolded proteins $[8,9]$. Although the mechanism causing diabetes is unclear, defects in EIF2AK3 may cause ER stress in the $\beta$-cell from misfolded proteins due to the high demand for insulin

Table 1 Key genes associated with neonatal diabetes mellitus

\begin{tabular}{|c|c|c|c|}
\hline Gene & Location & Inheritance & Clinical features \\
\hline \multirow[t]{2}{*}{ PLAGLI, HYMAI } & $6 q 24$ & $\begin{array}{l}\text { Variable } \\
\text { (imprinting) }\end{array}$ & Transient NDM \\
\hline & & & $\begin{array}{l} \pm \text { Macroglossia, } \\
\pm \text { Umbilical Hernia, } \\
\pm \text { Other features if } \\
\text { part of generalized } \\
\text { hypomethylation } \\
\text { syndrome }\end{array}$ \\
\hline KCNJ11 & $11 p 15.1$ & $\begin{array}{l}\text { De novo, } \\
\text { Dominant or } \\
\text { Recessive }\end{array}$ & $\begin{array}{l}\text { Permanent or Transient } \\
\text { NDM, } \pm \text { Developmental } \\
\text { delay, epilepsy, neonatal } \\
\text { diabetes (DEND) syndrome }\end{array}$ \\
\hline$A B C C 8$ & 11 p15.1 & $\begin{array}{l}\text { De novo, } \\
\text { Dominant or } \\
\text { Recessive }\end{array}$ & $\begin{array}{l}\text { Transient or Permanent } \\
\text { NDM }, \pm \text { DEND syndrome }\end{array}$ \\
\hline EIF2AK3 & $6 \mathrm{q} 22.1$ & Recessive & $\begin{array}{l}\text { Wolcott-Rallison Syndrome: } \\
\text { Permanent NDM } \\
\text { Short stature } \\
\text { Bone dysplasia } \\
\text { Hepatic dysfunction }\end{array}$ \\
\hline INS & $11 \mathrm{p} 15.5$ & Recessive & $\begin{array}{l}\text { Isolated permanent or } \\
\text { transient NDM }\end{array}$ \\
\hline GCK & 7p15-p13 & Recessive & Isolated permanent NDM \\
\hline
\end{tabular}

The most common genes associated with neonatal diabetes mellitus are described with key clinical features and mode of inheritance. Adapted from [2]. Genes associated with abnormal pancreas development are described in Table 2 secretion, eventually leading to $\beta$-cell apoptosis. Alternatively, diabetes may be linked to reduced $\beta$-cell proliferation with abnormal insulin trafficking and secretion, as observed in EIF2AK3 knockout mice [9].

Permanent NDM can also result from pancreatic agenesis or hypoplasia, which has been linked to mutations in transcription factors important for pancreatic and $\beta$ cell development. The most common of these is GATA6 [10]. Other causes include mutations in $P D X 1$ and the $P T F 1 A$ enhancer causing isolated abnormal pancreas development, while mutations in PTF1A, RFX6, HNF1B and GATA4 are associated with both pancreatic and extra-pancreatic abnormalities (Table 2) [11-16]. GATA6 is one of a family of evolutionarily conserved transcription factors recognizing the A/T-GATA-A/G consensus sequence, with key roles in the development and differentiation of multiple cell lineages and tissues [17, 18]. Heterozygous inactivating mutations in GATA6 were identified through a whole exome sequencing strategy in $15 / 27$ (56\%) individuals with pancreatic agenesis, defined as NDM requiring insulin treatment and exocrine pancreatic insufficiency requiring enzyme replacement. This is a syndromic form of NDM associated with extrapancreatic features including cardiac, hepatobiliary, gastrointestinal, neurocognitive and other endocrine involvement. Since its initial discovery, the phenotypic spectrum of GATA6 haploinsufficiency in humans has proven to be more diverse than initially appreciated, and although the initial cases were de novo, several instances of inherited GATA6 mutations have now been described [19-21]. This report describes three siblings with inherited GATA6 haploinsufficiency and the rare finding of parental mosaicism.

\section{Case presentation}

The proband was born at 37 weeks gestation after a pregnancy complicated by severe intrauterine growth restriction, reflected in the birth weight of $1.74 \mathrm{~kg}(<3 \mathrm{rd}$ percentile, -4 standard deviations). He was the first child of non-consanguineous parents of French Canadian background. Hyperglycemia occurred within the first $12 \mathrm{~h}$ of life and neonatal diabetes mellitus was diagnosed. An initial ultrasound visualized only the head of the pancreas, suggesting pancreatic hypoplasia. He was placed on subcutaneous insulin therapy with adequate glycemic control. Moderate valvular pulmonary stenosis and a patent ductus arteriosus (PDA) were also diagnosed and valvuloplasty was performed in the neonatal period.

At several months of age, recurrent episodes of hypoglycemia with decreasing insulin requirements began to occur. He was diagnosed with pancreatic exocrine insufficiency (PI) based on the recurrent hypoglycemia, poor weight gain and low stool fecal 
Table 2 Genes associated with neonatal diabetes mellitus and abnormal pancreas development

\begin{tabular}{|c|c|c|c|c|}
\hline Gene & Location & Inheritance & Clinical features & Reference \\
\hline PDX1 & $13 q 12.1$ & Recessive & $\begin{array}{l}\text { IUGR, } \\
\text { Pancreatic agenesis, } \\
\text { Permanent NDM, PI }\end{array}$ & [11] \\
\hline PTF1A enhancer & 10p12.2 & Recessive & $\begin{array}{l}\text { IUGR, Pancreatic agenesis, } \\
\text { Permanent NDM, PI }\end{array}$ & [12] \\
\hline PTF1A & 10p12.2 & Recessive & $\begin{array}{l}\text { IUGR, } \\
\text { Pancreatic agenesis, } \\
\text { Permanent NDM, variable PI, } \\
\text { Cerebellar } \\
\text { hypoplasia/aplasia }\end{array}$ & [13] \\
\hline RFX6 & $6 q 22.1$ & Recessive & $\begin{array}{l}\text { IUGR, Annular/hypoplastic pancreas, } \\
\text { Permanent NDM, } \\
\text { Chronic diarrhea, } \\
\text { Biliary and intestinal abnormalities }\end{array}$ & {$[14,32-35]$} \\
\hline HNF1B & $17 q 21.3$ & Dominant & $\begin{array}{l}\text { IUGR, } \\
\text { Pancreas hypoplasia, } \\
\text { Renal cysts }\end{array}$ & [15] \\
\hline GATA4 & $8 p 23.1$ & Dominant & $\begin{array}{l}\text { IUGR, } \\
\text { Pancreatic hypoplasia/agenesis, } \\
\text { Congenital heart defects, } \\
\text { Developmental delay }\end{array}$ & {$[16]$} \\
\hline
\end{tabular}

Genes in addition to GATA6 associated with both isolated diabetes and extra-pancreatic features are described with key clinical features and mode of inheritance

elastase, leading to initiation of pancreatic enzyme replacement. At 8 months of age, he was readmitted for severe failure to thrive and hypoglycemia secondary to inadequately treated PI, heart failure from the persistent PDA and a previously undiagnosed congenital diaphragmatic hernia. Intestinal malrotation was also noted. His medical management was optimized and he underwent repair of the PDA, diaphragmatic hernia and intestinal malrotation. At the time of surgery, no pancreatic tissue or gallbladder could be identified, demonstrating both pancreatic and gallbladder agenesis.

Despite improvement in his nutritional and overall health status, he continued to have episodes of early morning hypoglycemia, presumably due to deficient glucagon secretion. This was managed with feeds of uncooked cornstarch to provide a source of slowlyreleased glucose while on insulin injections and, when transitioned to pump therapy, with low basal insulin rates. Control of both the diabetes and exocrine insufficiency have been adequate with no evidence of malabsorption. There has been no clinical evidence of other endocrine dysfunction and thyroid function testing has been normal. He has also demonstrated appropriate neurocognitive development as of 9 years of age. Previous testing of the PDX1 gene, a recognized cause of pancreatic agenesis (Table 2) as well as broader genetic analysis through the 1,000,000 Single Nucleotide Polymorphism project were unrevealing.

A second pregnancy was terminated at 20 weeks due to complex congenital heart disease. Examination of the abortus revealed a male fetus with tetralogy of Fallot, congenital diaphragmatic hernia, severe pancreatic hypoplasia, gallbladder agenesis and intestinal non-rotation (Fig. 1, individual IIB). Subsequently, two male infants were born. The youngest child was found to have a PDA requiring procedural intervention, left pulmonary artery stenosis, and moderate atrial septal defect (Fig. 1, individual IID). Neither the remaining sibling nor either parent have any clinical evidence of diabetes, pancreatic exocrine insufficiency or cardiac disease.

\section{Methods \\ GATA6 sequencing}

Genomic DNA was extracted from peripheral leukocytes using standard procedures. Exons 2-7 and the exon/intron boundaries of the GATA6 gene were analyzed by Sanger sequencing as described previously. Exon 1 is a non-coding exon and was not sequenced [10]. Sequencing reactions were run on an ABI3730 capillary machine (Applied Biosystems, Warrington, U.K.) and analyzed using Mutation Surveyor v4.0.6 (SoftGenetics, State College, PA) (GATA6 nucleotide reference NM_005257.3). Allele frequency was quantified by nextgeneration sequencing as previously described [22].

\section{Histology}

Immunohistochemistry and staining for hematoxylin, phloxine, saffron were performed using standard procedures on slides of pancreatic tissue obtained at autopsy from the abortus (Fig. 1, individual IIB). For the immunohistochemistry, antibodies were used to detect insulin, glucagon and somatostatin. 


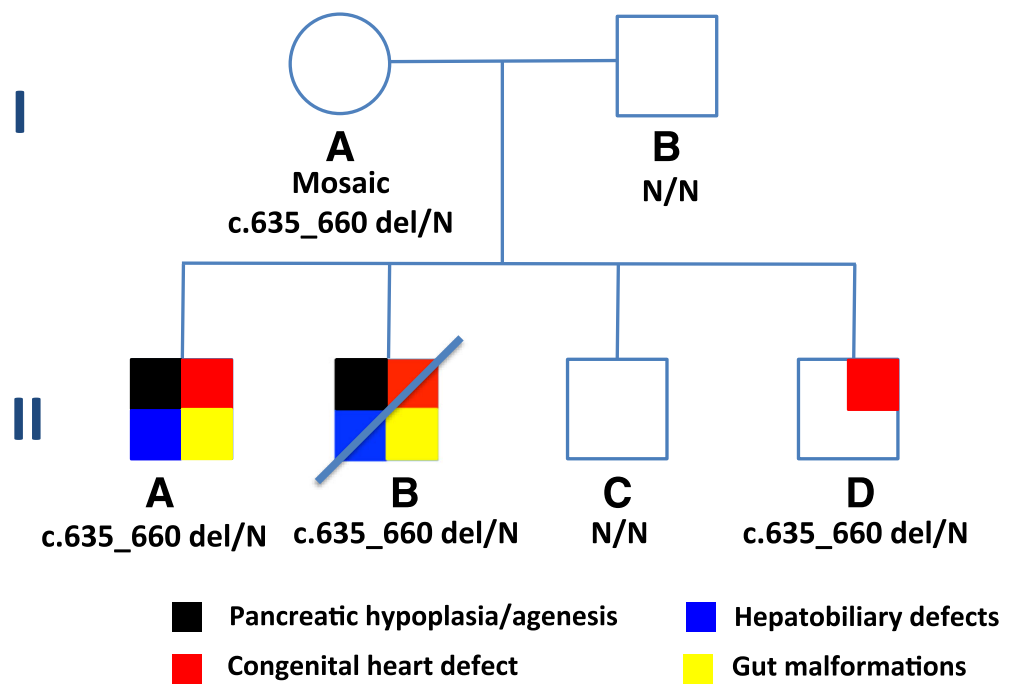

Fig. 1 Family Pedigree. The proband (II-A) and abortus (II-B) have multiple congenital anomalies including severe pancreatic agenesis/hypoplasia, while one sibling (II-D), also heterozygous for the same mutation, has isolated congenital cardiac anomalies including a PDA, left pulmonary artery stenosis, moderate atrial septal defect. The father and remaining sibling are negative for the mutation. The genotypes are provided below each symbol, $\mathrm{N}$ denotes the wildtype allele

\section{Results}

Given the similarity between the proband's spectrum of congenital anomalies and the clinical phenotype of GATA6 mutations, Sanger sequencing of exons $2-7$ of the GATA6 gene was performed in peripheral leukocytes. A novel c.635_660del frameshift mutation (p.Pro212fs) was identified in the proband. The mutation is located in exon 2 , within the transcriptional activation domain, and is predicted to result in inclusion of a premature stop codon and likely degradation of the gene transcript by nonsensemediated decay (Fig. 2). The mother, the abortus and the sibling with the congenital heart defect were also found to carry the mutation (Fig. 1). Notably, the mother, who has no clinical evidence of diabetes, including gestational diabetes or cardiac disease, was found to be mosaic for the mutation (Fig. 1, individual IA). This was confirmed and quantified by next-generation sequencing, revealing $11 \%$ mosaicism in peripheral blood. The father and the remaining sibling's testing were negative.

Histological analysis of the pancreas from the abortus (Fig. 1, individual IIB) demonstrated well-formed islets despite severe pancreatic hypoplasia (Fig. 3). The majority of islet cells stained positive for insulin and were surrounded by smaller populations of glucagon and somatostatin positive cells, demonstrating normal islet morphology.

\section{Discussion}

We describe three siblings heterozygous for the same GATA6 mutation inherited via parental mosaicism, yet

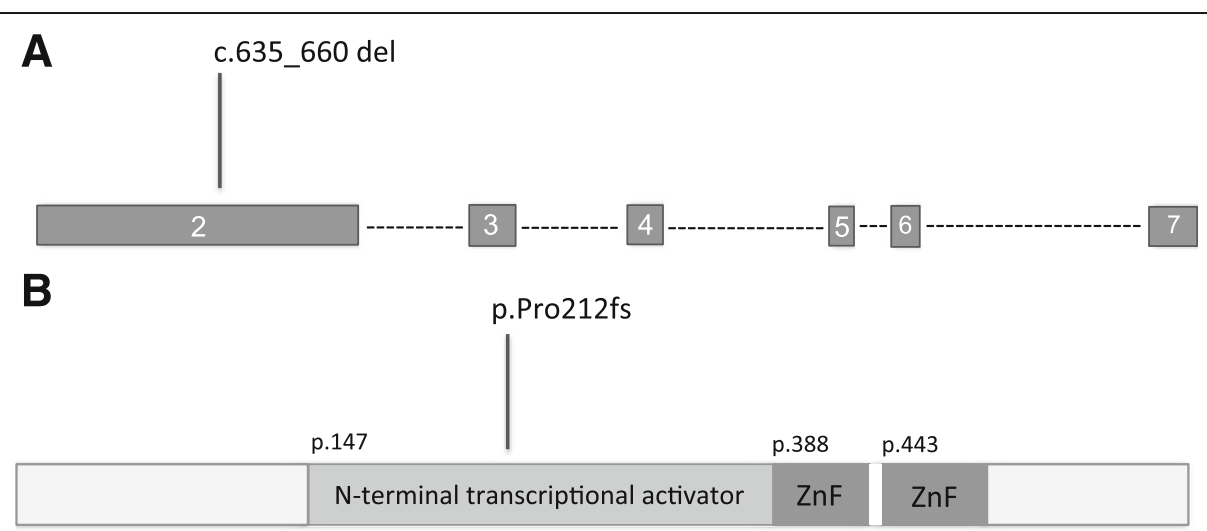

Fig. 2 Genomic and protein positions of the novel GATA6 mutation. a Exons 2 to 7 with the location of the novel deletion described are shown. b The frameshift resulting from the deletion is shown with its location in the transcriptional activation domain. The numbers refer to the amino acid position of the latter domain and the DNA-binding zinc fingers ( $\mathrm{nnF}$ ) 


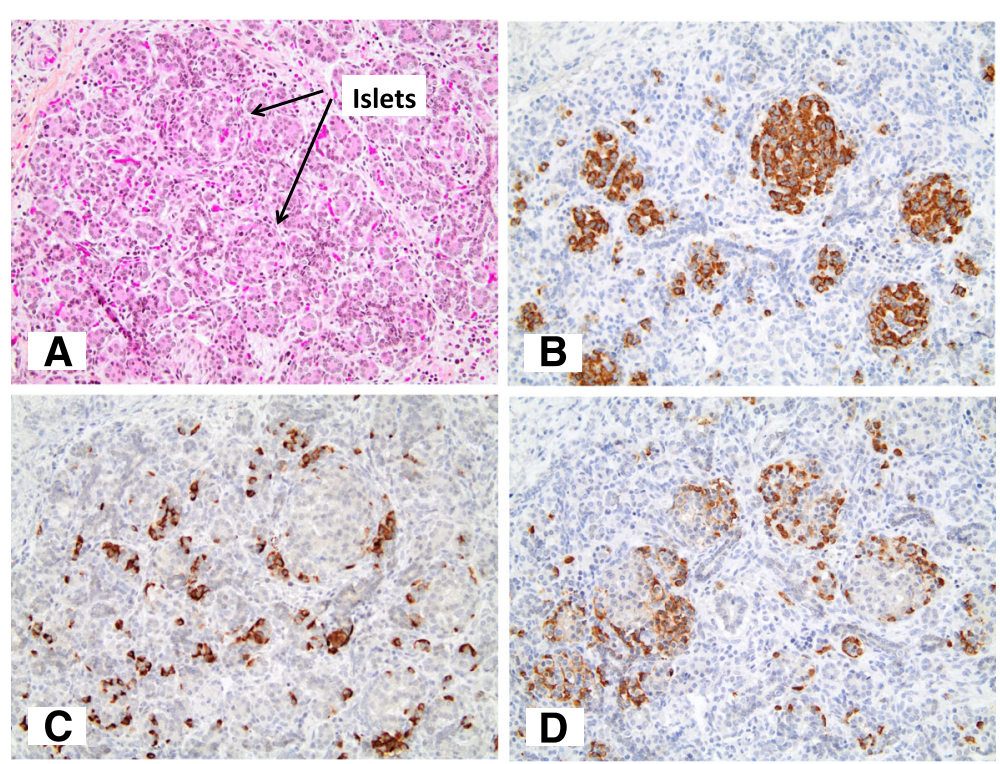

Fig. 3 Islet morphology is preserved with appropriate distribution of insulin- and glucagon-positive cells despite severe pancreas hypoplasia. Pancreas sections from individual II-B in Fig. 1 were stained using haematoxylin, phloxine and saffron staining (a), and immunohistochemistry for insulin, glucagon and somatostatin (b to $\mathbf{d}$ ). Islets were identified (a) demonstrating normal morphology with central insulin (b), peripheral glucagon (c) and somatostatin staining (d). All images were photographed at 200x magnification

with widely different manifestations, further defining the clinical phenotype associated with this rare disease. Since the initial report of heterozygous GATA6 mutations as the most common cause of pancreatic agenesis or hypoplasia, a much greater degree of phenotypic variability has been recognized for both pancreatic and extra-pancreatic features [10, 19]. Diabetes mellitus is the most common pancreatic feature in $98 \%$ of cases
(Table 3). Although the majority of cases present with $\mathrm{NDM}$, in others diabetes develops later in life or has yet to occur by adulthood. Similarly, although clinical PI has been reported in $81 \%$ of cases, subclinical PI and normal exocrine function have also been described (Table 3) $[10,19,23]$. Of the extra-pancreatic features, cardiac defects are the most common, in $88 \%$ of cases, although gastrointestinal, hepatobiliary, neurodevelopmental and

Table 3 Phenotypic spectrum associated with GATA6 haploinsufficiency

\begin{tabular}{|c|c|c|}
\hline Clinical features & Spectrum and severity & $\begin{array}{l}\text { Patients with GATA6 } \\
\text { mutation, } N=41(\%)\end{array}$ \\
\hline \multicolumn{3}{|l|}{ Pancreatic Features } \\
\hline Diabetes Mellitus & Neonatal/adult-onset & $\begin{array}{l}\text { Total 40/41 (98), } \\
\text { NDM 33/41 (81) }{ }^{\mathrm{a}}{ }^{\prime} \\
\text { Child-onset 4/41 (10) }{ }^{\mathrm{b}} \text {, } \\
\text { Adult-onset 3/41 (7) }\end{array}$ \\
\hline Exocrine Insufficiency & Clinical/subclinical $^{d}$ & $\begin{array}{l}\text { Total 33/37 (89) } \\
\text { Clinical 30/37 (81) }\end{array}$ \\
\hline \multicolumn{3}{|l|}{ Extra-Pancreatic Features } \\
\hline Cardiac & Isolated septal defect/multiple complex defects & $36 / 41(88)$ \\
\hline Hepatobiliary & Gallbladder atresia, biliary atresia & $13 / 41(32)$ \\
\hline Gastrointestinal & Umbilical hernia, diaphragmatic hernia, intestinal malrotation & $8 / 41(20)$ \\
\hline Other Endocrine & Hypothyroidism, pituitary agenesis & $7 / 41(17)$ \\
\hline Neurocognitive & Developmentally appropriate/mild learning difficulties/severe developmental delay & $13 / 41(32)$ \\
\hline Genitourinary & Bicornuate uterus, hydronephrosis, hydroureter & $2 / 41(5)$ \\
\hline
\end{tabular}

Summary of the pancreatic and extra-pancreatic features of the published cases to date, demonstrating the variability of the phenotype [10, 19-21, 23-29]. ${ }^{a} \mathrm{NDM}$ group includes one case of transient NDM, ${ }^{b}$ childhood-onset group includes one case of impaired glucose tolerance in adolescence, ${ }^{c}$ four cases were excluded as no information on exocrine insufficiency was provided, ${ }^{d}$ subclinical was defined as low fecal elastase or positive fecal fat in the absence of clinical symptoms or need for pancreatic enzyme replacement 
other endocrine involvement have also been reported (Table 3) [10, 19-21, 23-29]. The family described here illustrates this clinical variability. The proband has NDM and PI, with significant cardiothoracic, gastrointestinal and biliary involvement. A similar phenotype was seen in the second affected sibling whereas in contrast, the third sibling has isolated cardiac involvement. Thus, GATA6 haploinsufficiency needs to be strongly considered as a potential cause in cases of diabetes secondary to abnormal pancreas development and, if confirmed, a thorough, multi-system assessment, particularly cardiac, should be performed to evaluate for other abnormalities. Consideration should also be given to screening for glycemic abnormalities in those whom diabetes has not yet developed.

Although most cases of GATA6 mutations are de novo, several cases of dominant inheritance have been reported $[10,19]$. The family described here is notable for being amongst these inherited cases and moreover, is only the second report of parental mosaicism [19]. In the previous report, the parent was known to have a congenital heart defect, whereas in our case the mother has no known cardiac abnormalities or pancreatic phenotype. Presumably differing levels of tissue mosaicism is key. Since three out of four offspring inherited the mutation, the level of mosaicism is likely significantly higher in the germline compared to other tissues in our case given the absence of other system involvement and almost certainly higher than the $11 \%$ detected in peripheral blood. Accordingly, testing of parents and other potentially affected family members should be performed, even in individuals without an obvious clinical phenotype.

The mechanism underlying the variable expressivity of GATA6 haploinsufficiency remains unclear with no obvious genotype-phenotype relationship [19]. Histologically, grossly preserved islet morphology was observed, which contrasts with murine models demonstrating abnormal morphogenesis with failure of progenitor cells to differentiate into endocrine and exocrine lineages (Fig. 3). However, humans appear to have greater sensitivity to GATA6 gene dosage as both Gata4 alleles in addition to at least one Gata6 allele must be inactivated in mice to cause pancreatic abnormalities [30,31]. Although not explored in this report, at a molecular level, there are several potential mechanisms. In vitro studies have shown that missense mutations affecting highly conserved zinc finger residues result in failure to bind target promoters in luciferase reporter promoter assays $[10,19,27]$. Given the location of the novel frameshift mutation described here in the transactivation domain, there could be an impact on downstream genetic targets through altered binding of co-regulatory factors. However, the most likely explanation is that the introduction of a premature termination codon results in a reduction in GATA6 mRNA transcript levels through nonsense- mediated decay, as previously described [26]. Variable efficiency of this decay in different tissues could contribute to the phenotypic variability. Modifier genes, epigenetic mechanisms and environmental factors represent other potential mechanisms that could also contribute to the variability associated with GATA6 heterozygous mutations.

\section{Conclusions}

Heterozygous mutations in the GATA6 transcription factor gene are the most common cause of neonatal diabetes due to pancreatic agenesis. We describe three siblings heterozygous for the same GATA6 mutation inherited via parental mosaicism, a rare occurrence. Their markedly different manifestations illustrate both the importance of GATA6 for pancreas development as well as the phenotypic variability of GATA6 haploinsufficiency. Elucidating the mechanisms underlying the phenotype and its variability will improve our understanding of pancreas development and may provide insights into the mechanisms underlying other forms of abnormal pancreas development and neonatal diabetes.

\begin{abstract}
Abbreviations
IUGR: intrauterine growth restriction; NDM: neonatal diabetes mellitus; PDA: patent ductus arteriosus; PI: pancreatic exocrine insufficiency
\end{abstract}

\section{Acknowledgments \\ The authors thank the family who participated in this study. We also thank A. Cuellar for his technical assistance regarding the immunohistochemistry.}

\section{Funding}

JJM receives support from the Dr. Eleanor Mackenzie Harpur Pediatric Endowment Fund. The genetic testing in this report was funded by the Wellcome Trust via a Senior Investigator Award to SE. EDF is a Naomi Berrie Fellow in Diabetes Research. SEF has a Sir Henry Dale Fellowship jointly funded by the Wellcome Trust and the Royal Society (Grant Number 105636/Z/14/Z).

\section{Availability of data and materials}

The anonymized data analyzed during the current study is available from the corresponding author on reasonable request. Primer sequences used for GATA6 sequencing are available in reference 10 and its supplementary information files.

\section{Authors' contributions}

JJM conceived of the study. GATA6 testing of the proband and family was coordinated by JJM and DY. SE, EDF and SF carried out the genetic analysis. MB performed and oversaw the histological analysis. DY wrote and JJM revised the manuscript. All authors read and approved the final manuscript.

\section{Authors' information}

Not applicable.

\section{Competing interests}

The authors declare that they have no competing interests.

\section{Consent for publication}

Written informed consent for publication of their clinical details and/or clinical images was obtained from the parents of the patients. Copies of the consent forms are available for review by the Editor of this journal. 


\section{Ethics approval and consent to participate}

The need for ethics approval from the institutional REB was waived as per provincial ethics and legal requirements. Consent was obtained as outlined above.

\section{Author details}

'Division of Pediatric Endocrinology Montreal Children's Hospital, McGill University Health Centre, 1001 Boulevard Decarie, Montreal H4A 3J1, Quebec, Canada. ${ }^{2}$ Institute of Biomedical and Clinical Science, University of Exeter Medical School, Barrack Road, Exeter EX2 5DW, UK. ${ }^{3}$ Department of Pathology Montreal Children's Hospital, McGill University Health Centre, 1001 Boulevard Decarie, Montreal H4A 3J1, Quebec, Canada.

Received: 1 September 2016 Accepted: 8 December 2016 Published online: 03 January 2017

\section{References}

1. Craig ME, Jefferies C, Dabelea D, Balde N, Seth A, Donaghue KC. Definition, epidemiology, and classification of diabetes in children and adolescents. Pediatr Diabetes. 2014;15 Suppl 20:4-17.

2. Rubio-Cabezas O, Hattersley AT, Njølstad PR, Mlynarski W, Ellard S, White N Chi DV, Craig ME. The diagnosis and management of monogenic diabetes in children and adolescents. Pediatr Diabetes. 2014;15 Suppl 20:47-64.

3. De Franco E, Flanagan SE, Houghton JA, Lango Allen H, Mackay DJ, Temple IK, Ellard S, Hattersley AT. The effect of early, comprehensive genomic testing on clinical care in neonatal diabetes: an international cohort study. Lancet. 2015; 386:957-63.

4. Grulich-Henn J, Wagner V, Thon A, Schober E, Marg W, Kapellen TM, Haberland H, Raile K, Ellard S, Flanagan SE, et al. Entities and frequency of neonatal diabetes: data from the diabetes documentation and quality management system (DPV). Diabet Med. 2010;27:709-12.

5. lafusco D, Massa O, Pasquino B, Colombo C, lughetti L, Bizzarri C, Mammi C, Lo Presti D, Suprani T, Schiaffini R, et al. Minimal incidence of neonatal/ infancy onset diabetes in Italy is 1:90,000 live births. Acta Diabetol. 2012:49:405-8

6. Shield JP, Temple IK, Sabin M, Mackay D, Robinson DO, Betts PR, Carson DJ, Cave $\mathrm{H}$, Chevenne D, Polak M. An assessment of pancreatic endocrine function and insulin sensitivity in patients with transient neonatal diabetes in remission. Arch Dis Child Fetal Neonatal Ed. 2004:89:F341-3.

7. Temple IK, Gardner RJ, Mackay DJ, Barber JC, Robinson DO, Shield JP. Transient neonatal diabetes: widening the understanding of the etiopathogenesis of diabetes. Diabetes. 2000;49:1359-66.

8. Karges B, Meissner T, Icks A, Kapellen T, Holl RW. Management of diabetes mellitus in infants. Nat Rev Endocrinol. 2012;8:201-11.

9. Julier C, Nicolino M. Wolcott-rallison syndrome. Orphanet J Rare Dis. 2010;5:29.

10. Lango Allen H, Flanagan SE, Shaw-Smith C, De Franco E, Akerman I, Caswell R, nternational Pancreatic Agenesis Consortium, Ferrer J, Hattersley AT, Ellard S. GATA6 haploinsufficiency causes pancreatic agenesis in humans. Nat Genet. 2011:44:20-2.

11. Stoffers DA, Zinkin NT, Stanojevic V, Clarke WL, Habener JF. Pancreatic agenesis attributable to a single nucleotide deletion in the human IPF1 gene coding sequence. Nat Genet. 1997;15:106-10.

12. Weedon MN, Cebola I, Patch AM, Flanagan SE, De Franco E, Caswell R, Rodriguez-Segui SA, Shaw-Smith C, Cho CH, Lango Allen H, et al. Recessive mutations in a distal PTF1A enhancer cause isolated pancreatic agenesis. Nat Genet. 2014;46:61-4.

13. Sellick GS, Barker KT, Stolte-Dijkstra I, Fleischmann C, Coleman RJ, Garrett C, Gloyn AL, Edghill EL, Hattersley AT, Wellauer PK, et al. Mutations in PTF1A cause pancreatic and cerebellar agenesis. Nat Genet. 2004;36:1301-5.

14. Concepcion JP, Reh CS, Daniels M, Liu X, Paz VP, Ye H, Highland HM, Hanis CL, Greeley SA. Neonatal diabetes, gallbladder agenesis, duodenal atresia, and intestinal malrotation caused by a novel homozygous mutation in RFX6. Pediatr Diabetes. 2014;15:67-72.

15. Yorifuji T, Kurokawa K, Mamada M, Imai T, Kawai M, Nishi Y, Shishido S, Hasegawa Y, Nakahata T. Neonatal diabetes mellitus and neonatal polycystic, dysplastic kidneys: Phenotypically discordant recurrence of a mutation in the hepatocyte nuclear factor-1beta gene due to germline mosaicism. J Clin Endocrinol Metab. 2004;89:2905-8.
16. Shaw-Smith C, De Franco E, Lango Allen H, Batlle M, Flanagan SE, Borowiec M, Taplin CE, van Alfen-van der Velden J, Cruz-Rojo J, Perez de Nanclares G, et al. GATA4 mutations are a cause of neonatal and childhood-onset diabetes. Diabetes. 2014:63:2888-94.

17. Viger RS, Guittot SM, Anttonen M, Wilson DB, Heikinheimo M. Role of the GATA family of transcription factors in endocrine development, function, and disease. Mol Endocrinol. 2008;22:781-98.

18. Minami K. GATA transcription factors: New key regulators in pancreas organogenesis. J Diab Investig. 2013;4:426-7.

19. De Franco E, Shaw-Smith C, Flanagan SE, Shepherd MH, International NDM Consortium, Hattersley AT, Ellard S. GATA6 mutations cause a broad phenotypic spectrum of diabetes from pancreatic agenesis to adult-onset diabetes without exocrine insufficiency. Diabetes. 2013;62:993-7.

20. Bonnefond A, Sand O, Guerin B, Durand E, De Graeve F, Huyvaert M, Rachdi L, Kerr-Conte J, Pattou F, Vaxillaire M, et al. GATA6 inactivating mutations are associated with heart defects and, inconsistently, with pancreatic agenesis and diabetes. Diabetologia. 2012;55:2845-7.

21. Yorifuji T, Kawakita R, Hosokawa Y, Fujimaru R, Yamaguchi E, Tamagawa N. Dominantly inherited diabetes mellitus caused by GATA6 haploinsufficiency: variable intrafamilial presentation. J Med Genet. 2012;49:642-3.

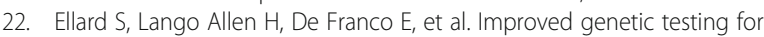
monogenic diabetes using targeted next-generation sequencing. Diabetologia. 2013;56:1958-63.

23. Catli G, Abaci A, Flanagan SE, De Franco E, Ellard S, Hattersley A, Guleryuz H, Bober E. A novel GATA6 mutation leading to congenital heart defects and permanent neonatal diabetes: a case report. Diab Metab. 2013:39:370-4.

24. Gong M, Simaite D, Kuhnen P, Heldmann M, Spagnoli F, Blankenstein O, Hubner N, Hussain K, Raile K. Two novel GATA6 mutations cause childhoodonset diabetes mellitus, pancreas malformation and congenital heart disease. Horm Res Paediatr. 2013;79:250-6.

25. Eifes S, Chudasama KK, Molnes J, Wagner K, Hoang T, Schierloh U, RocourBrumioul D, Johansson S, Njolstad PR, de Beaufort C. A novel GATA6 mutation in a child with congenital heart malformation and neonatal diabetes. Clin Case Rep. 2013;1:86-90.

26. Suzuki S, Nakao A, Sarhat AR, Furuya A, Matsuo K, Tanahashi Y, Kajino H, Azuma $H$. A case of pancreatic agenesis and congenital heart defects with a novel GATA6 nonsense mutation: evidence of haploinsufficiency due to nonsense-mediated mRNA decay. Am J Med Genet A. 2014;164A:476-9.

27. Chao CS, McKnight KD, Cox KL, Chang AL, Kim SK, Feldman BJ. Novel GATA6 mutations in patients with pancreatic agenesis and congenital heart malformations. PLoS One. 2015;10:e0118449.

28. Tuhan H, Catli G, Anik A, Ozmen D, Turkmen MA, Bober E, Abaci A. Neonatal diabetes mellitus due to a novel mutation in the GATA6 gene accompanying renal dysfunction: a case report. Am J Med Genet A. 2015;167A:925-7.

29. Stanescu DE, Hughes N, Patel P, De Leon DD. A novel mutation in GATA6 causes pancreatic agenesis. Pediatr Diabetes. 2015;16:67-70.

30. Carrasco M, Delgado I, Soria B, Martin F, Rojas A. GATA4 and GATA6 control mouse pancreas organogenesis. J Clin Invest. 2012;122:3504-15.

31. Xuan S, Borok MJ, Decker KJ, Battle MA, Duncan SA, Hale MA, Macdonald RJ, Sussel L. Pancreas-specific deletion of mouse Gata4 and Gata6 causes pancreatic agenesis. J Clin Invest. 2012;122:3516-28.

32. Chappell L, Gorman S, Campbell F, Ellard S, Rice G, Dobbie A, Crow Y. A further example of a distinctive autosomal recessive syndrome comprising neonatal diabetes mellitus, intestinal atresias and gall bladder agenesis. Am J Med Genet A. 2008;146A:1713-7.

33. Mitchell J, Punthakee Z, Lo B, Bernard C, Chong K, Newman C, Cartier L, Desilets V, Cutz E, Hansen IL, et al. Neonatal diabetes, with hypoplastic pancreas, intestinal atresia and gall bladder hypoplasia: search for the aetiology of a new autosomal recessive syndrome. Diabetologia. 2004;47:2160-7.

34. Smith SB, Qu HQ, Taleb N, Kishimoto NY, Scheel DW, Lu Y, Patch AM, Grabs R, Wang J, Lynn FC, et al. Rfx6 directs islet formation and insulin production in mice and humans. Nature. 2010;463:775-80.

35. Spiegel R, Dobbie A, Hartman C, de Vries L, Ellard S, Shalev SA. Clinical characterization of a newly described neonatal diabetes syndrome caused by RFX6 mutations. Am J Med Genet A. 2011;155A:2821-5. 